\title{
The Effect of Geometry Journal Writing on Pre-Service Teachers
}

\author{
Sana Saeed Al-Haddad \\ Bahrain Teachers College, Bahrain
}

\begin{abstract}
This action research investigates the effects of using homework journals writing in Geometry on pre-service teacher's preparation for summative test. As well as investigating the impact on future teacher's career. This study was conducted on 38 pre-service teachers in the second year of the BE.d program in the Bahrain Teachers College. Those student teachers have been divided into two classes called cycle one and two. Cycle one was the class that was using the homework journal writing assignment. As for cycle two, they had conventional type homework, where the student teachers solve some questions about geometry in the text book. The data collected from students is from the students' journal entries- based on topics in geometry - and questionnaire survey. The results show that students in cycle one shows a slight improvement in the student's summative test. Whereas students; of cycle two achieved slightly lower grades than cycle one. However; writing the journal has shown that it helps the student in his career later on, because it helps build his/her communicational skills.
\end{abstract}

\section{Introduction}

Through my several years of teaching BE.d students Geometry, I realized that the student teachers were not achieving the grades I hoped they would achieve in their summative tests. Like every good teacher, I wanted to help my students, so I tried to figure out why the students had such low marks. The students told me that the reason behind their poor performance in the summative test was because they did not have enough time to prepare for the exam. They used conventional methods of reviewing such as solving exercises in the text book, and going over the lessons and trying to memorize things one or two days before the exam. This inspired me to look at different ways of improving my students' performances. I wanted to implement a method that will not affect the course, or my teaching methods. This method had to also be enjoyed by the students and at the same time be beneficial to them. I started to look at different methods that will improve the students' grades and still meet all the requirements I had set. During my research, I noticed that journal writing was very successful in conceptual understanding and procedural knowledge in different areas of mathematics such as Algebra and statistics [2, 4, 11, 16 and 17]. Many researchers showed the effect of journal writing on students mathematical thinking [3, 6, 8 and 30]. In addition, BangertDrowns et al had established that student academic achievement increased in almost half of the courses, although mostly small and positive [1]. However, I was not able to find any studies showing the effect of journal writing in studying geometry. Also, most of the studies were conducted in grade school rather than in universities. Furthermore, the research done by the other researchers was done in the western and other countries not in the Arabian Gulf [1]. I hoped that using journal writing will help the student teachers achieve better grades in the geometry summative test. The fact that journal writing was very successful in many areas convinced me to do this action research on the effect of Geometry Journal on pre-service teachers' preparation for the summative test.

\section{Purpose of the study}

This Action Research aims to study the effect of Geometry journal writings on the pre-service teachers' preparation for summative the test. What aroused the study of this research was the excuse my students gave me in previous years, for not achieving good scores on summative test. Therefore I engaged in this investigation to eliminate the excuse, and help my students to gain better grades. The excuse which crippled the student's grades was the lack of time to prepare for the summative test. I resorted to Journal writing because it will help the students prepare for the exams three weeks before rather than what the other students are doing, which is studying for the exams one or two days before. I also think that writing the journal might improve their communicational skills. Therefore the purpose of this study is to find out if implementing the journal writing method will improve the student's performance in the geometry course. 


\section{Research background, planning and methodology}

\subsection{Research background}

Journal writing is essentially an exercise teachers make the students do in which whatever the students learns they are able to convey what they have learned, their perspective on a topic, or even some of their experiences on a concept. It is also identified as a tool allowing learners to construct and transform their thinking and ideas as they manipulate, integrate, and restructure knowledge through using and reflecting on prior knowledge, concepts, and beliefs [2], [31]. The interest in journal writing in education has been rekindled. Its role in learning and teaching has been the concern of educators for a long time. Dewey [5], the father of experiential education, always stressed the importance of reflection in education. Reflection can be thought of as a type of journal writing because it allows the student to convey his experiences, just like the journal writing. Also, writing is one form of communication. Vigotsky [32] viewed that students develop higherorder thinking through language. Lindquist \& Elliot consider that learning and teaching mathematics affected by language. He said: "How do we learn a language? We talk, we listen, we read, we write. We build the concepts underlying the ideas so we can communicate with meaning" [13, p.5-6]. National Council of Teachers of Mathematics [21] identified that writing is an important skill for all math students and the reason behind combining writing into mathematics courses is that writing assignments will make students better writers or Mathematical communicators. Furthermore, writing in mathematics classroom allows a teacher to "monitor a student's capacity to analyze situations, frame and solve problems, and make sense of mathematical concepts and procedures" [21, p. 19].

There is no lack of research regarding the benefits of journal writing in mathematics learning and understanding. Many research such as Pugalee \& Lim [17]; Pugalee[16]; Nelson[22]; Tynjala, Mason $\&$ Lonka [29] advocated the use of writing-to-learn mathematics. I believe the literature lacks in the area of writing journals and mathematics achievement on the specific cognitive levels. Although some researchers reported a positive effect of writing on general mathematics achievement at elementary and high school levels [7, 10, 20, 26]. On the other hand, Madden found small positive effect for conceptual understanding of one chapter test but not the cumulative test [18]. As well Phillips [14] did not find significant differences by writing in trigonometry classes. Therefore the current study will explore effect of journal writing in geometry on student's preparation for summative test and their future teaching profession.

\subsection{Planning and methodology}

This action research was conducted in the first semester of the academic year of 10/11 in Bahrain Teachers College (BTC). The sample included 38 undergraduate students in the second year enrolled in BE.d Mathematics and science program. In the beginning, I add graded assignments in the student's syllabus; it was called homework journal writing assignments. The reason why I decided to make the assignment graded is to ensure that all my students will take the assignment seriously. Hahnemann [9] and Williams [33] weighted the journals as $10 \%$ of a grade in a course because they felt it would motivate the students to write thoroughly and with meaning. The students themselves however, did not know that I will be using the information collected in my research. At the time, I thought that the only way to get proper results was to keep the students from knowing that I was going to collect their results. This way, the results represent the students' true performance, because the student will not be conscious of the fact that he is being studied. However, since the assignment is graded, the student will also try to perform his best. To do all this, I decided to not give the students a consent form even though I knew that doing so is considered unmoral.

My group "cycle one", consisting of 19 student teachers had the journal writing assignment to do three weeks before the final exam. They had ten journal entries to do; they had to do with different topics in the course. As for the 19 students in group "cycle two", they prepared for the exam in the more conventional way, where they would review the lectures less than a week before the summative test. I was instructing both groups all the semester with the same content, materials, teaching methods, and activities.

\section{First Cycle}

\subsection{Planning and Action}

After covering most of the topics in class with the students throughout the semester, I assigned the group their first journal to complete at home. The journal consists of questions that they had to answer in their own words. The questions showed whether they were able to understand the concepts rather than just answer the question. Over the course of 3 weeks, the group had to complete ten of these journals, all covering different topics in the semester's course. The journals were done individually. After the journal was handed to me, I graded them according to the rubric I had given them before we started the assignment. Then I gave them all feedback. At the 
end of the week, we discussed the assignment together, where they gave me feedback on what they thought of journal. The feedback they would give me will be one of the most important data I can collect from this study. The journals and rubrics were borrowed from Kaur [12]. In addition before the end of the semester, I gave the group surveys where they had to answer questions about their perceptions and ideas about the writing journals in geometry. I did not think of the questionnaire as an accurate representation of the students thoughts and opinions because some of them may not be bothered to answer in complete honesty or take the questionnaire seriously. However I will add a comment section to the questionnaire hoping that it will allow the students who really take the questionnaire seriously to express their selves better. While those who do not take the questionnaire seriously, will be exposed by the comment section, because if they decide to write something, it will be most likely without quality. As for those who write nothing, it will be even clearer that they are not taking the questionnaire seriously.

\subsection{Results}

Data was collected in two different ways for Cycle one, there were two different tools that helped us collect this data. The first tool was the summative test, which gave us a quantitative result. For Cycle one, the class average for the summative test was approximately $84 \%$ (see Table1). This reflects the average of 19 students in the cycle one group. The summative test contained questions of all types of levels of thinking and difficulties.

The second tool used was the survey questionnaire; it allowed us to collect qualitative information. This includes how they felt about the journal, and their overall perspective of the writing journal. All 19 students in cycle one had to complete and return the questionnaire at the end of the semester. Overall, most of the students saw the positive effect of the journal. One student said: "writing math journals helps in learning, because students can easily express what he had learned and apply what he had learned in open question instead of using traditional methods". Stewart and Chance [28] cited out that journal writings are giving to students to communicate about mathematics either cognitively or affectively. Many more students thought the same way as the pervious student. The students generally believed that the journals helped them, but they seem to have really seen the benefit in journal writing for their future as a teacher, for example, one of the students said: "In general, the course was useful and we will benefit from it in our teaching career". Samsa and Oddone pointed out, "...the more clearly and persuasively we write, the more positively will our Profession be viewed" [24]. One student in specific, used writing journals in the teacher practice session, she made her $4^{\text {th }}$ grade students complete a journal. However, not all feedback was positive; one student thought that they had not enough time to complete three to four journals a week. However, his argument is not justifiable since he said he did not have enough time because he was busy with other social events rather than his education.

At the end of each week, we would discuss their results and grades, and I also provide them some feedback. During the class discussion, the students would tell me what they thought of the assigned journals. One student in particular told me that the journal writing will help him revise for the final exam (figure1).This is because it kept the information he learned fresh in his mind, and thus he was looking forward to doing the exam.

\subsection{Reflection}

At the end of each week, I correct the students' journal writings. One thing I have noticed is that some of the students copy answers. However, this is not to cheat, but ensure they have the correct answer. The problem is, in these journals, there is no correct one answer. Since this assignment is done at home, I cannot prevent them from talking to one another. The problem is that the students are not able to think for themselves. They resort to checking what their classmate wrote so they can write the same.

To solve this problem, I should have required them to do this assignment in class, where we can allocate a certain amount of time in class where they can complete the assignment. This will ensure that the student teachers do not copy answers from one another. When this is done, each student will be forced to come up with his own answers. So not only is the student's communicational skill being developed, also his ability to think for him/herself, and develop his/her own ideas.

Thinking back to when I first assigned the journal writing to my students, I thought that ten journal entries were enough. This is because after the positive feedback I received from a majority of my students, I believe that more journals may prepare the students even better for the summative test. However, instead of correcting the increased number of journal entries by myself, I think it is better if we have students correct some of their own journals. This will allow me to request from students to write more journals by themselves so they can be prepared better for the summative test, and since the students already have the rubric, they can correct their own journals with my assistance. Moreover, it could be more beneficial to make each student correct the journal of his or her class mate using the rubric, this will give him/her the opportunity to practice correcting others work, such as his or her future students' school work and will subsequently gain 
the required experiences in the practice of correcting students' work.

Another problem I noticed is that when my students were assigned to the practice of writing journals, it was not started from the beginning of the semester, it was done in the last three weeks of the course. When they started, they found it was very difficult to complete the first two journals. The standard of the completed first few journals were not as good as the journals done later on. So, I found that I should have asked students to write journals from the beginning of the semester and not just at the last three weeks of the semester. Moreover, it is good idea to make it as an integrated part of the practice of teaching this course and others. This way, the students will be better prepared for the summative test, and will be able to write a better quality journals during the course work. Which will maximize the benefits of writing journal on their academic and professional life?

After completing the semester work in which I had implemented the practice of writing journals by the students, and looking back at how their grades turned out to be , made me realize that the journal writing does not only help the students to improve their understanding and practice, it had also helped me to understand my students even better. The journal writing made me aware of my students' strengths and weakness. The journal writing probed each student and highlighted where the student really understood the topic, and where he really needed improvements. Shaw [25] cited out that Mathematics teachers have an excellent chance to diagnose students' thought processes when they use the journal to ask students to explain their understanding of a concept. This also provides the teacher with a feedback on the effectiveness of teaching procedures. While I was reading the journal entries, I could also interpret other things such as whether the students need further preparation or not. This can be an important tool for any teacher. Stock [29] revealed that reading journal entries gives teachers insight the fundamental skills into how the student thinks and allows to assess the student's mastery of the material.

Another aspect I want to reflect on is that the survey I have prepared for the students is not much of use to me. This however; does not include the comments section in the survey. The comments section helped me a lot because the students answers were genuine, as for the other parts, the students did take them seriously and therefore scribbled in an answer. It also revealed that students developed positive attitude towards writing journal in this particular topics which was a geometry concepts. One of the comments was "Yes it was really nice, it was encouraging me to think and use high level of thinking, it is facilitating the revision for the final exam, journal writing was useful". Another student's comment "I think that writing math journals helped me in learning.....and how to answer open questions..." (see Figure 1). It is clearly that journal writing had a very positive impact on student's attitude towards journal writing.
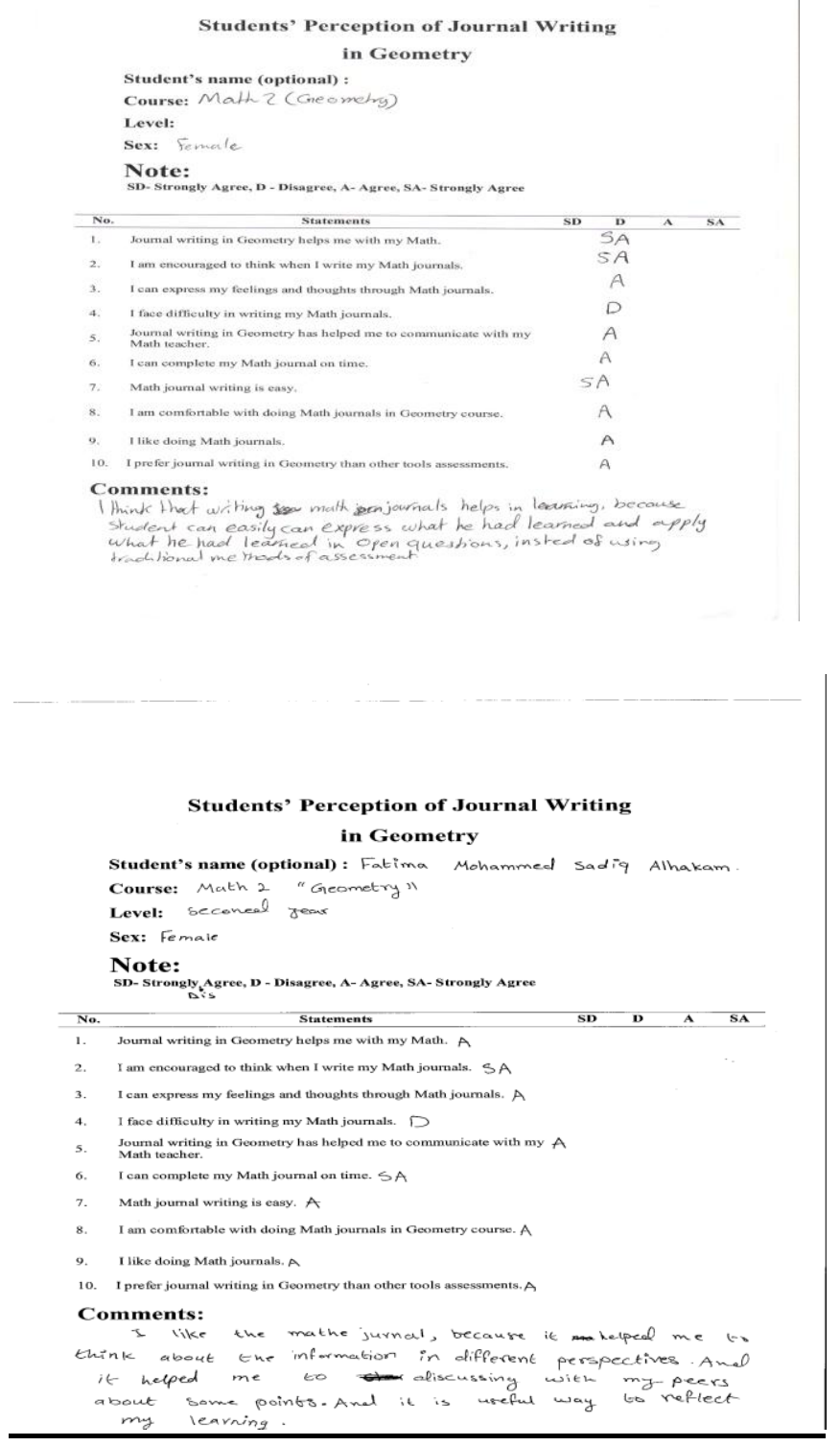

Figure 1. Sample of students' comments

\section{Second Cycle}

\subsection{Planning and Action}

For my students in cycle two, the same lessons that I covered with cycle one I covered with cycle two, and after that, I assigned homework to them from the text book. Where they were to independently do the work at home and return it back to me on the last week, just before the exam. That way, I know that the students revised less than a week before the exam. This simulates what the 
majority of my students say they do, where they only prepare a week or less before the exam. This assignment is graded, so this forces the student to do his work. Just like Cycle one, I had 19 students in cycle two.

\subsection{Results}

In cycle two, my students scored a little bit under the score of cycle one. This is consistent with [1], [20]. Cycle two scored 79 percent, 5 percent under cycle one (Table1).

Table 1. Comparison between cycle one and cycle two

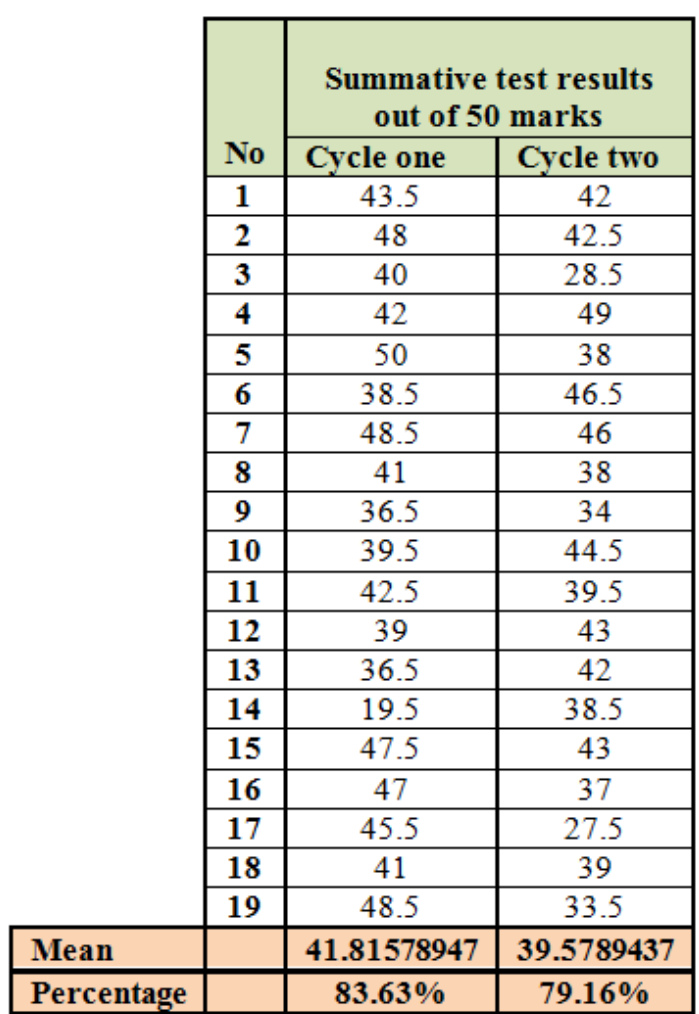

From the numerical results collected form Table 1, I conducted the T-test, and these were the results I got below. And from the T-test (Table2) $\mathrm{t}=1.09$, $\mathrm{p}=0.28>0.05$, we can conclude that there is no significant difference between the group one with homework writing journals assignments and the group two with conventional type homework. This aligned with (Madden [18]; Phillips[14] Porter \& Masingila [15].
Table 2. t-Test of the summative test

\begin{tabular}{|l|l|l|l|l|l|l|}
\hline \multicolumn{7}{|c|}{ Two-Sample T Test of the Summative Test Results } \\
\hline & $\mathrm{N}$ & $\begin{array}{l}\text { Mea } \\
\mathrm{n}\end{array}$ & $\begin{array}{l}\text { STANDARD } \\
\text { DEVIATION }\end{array}$ & Sig & $\mathrm{df}$ & $\mathrm{t}$ \\
\hline $\begin{array}{l}\text { Cycle } \\
\text { one }\end{array}$ & 19 & 41.8 & 6.88 & 0.28 & 36 & 1.086 \\
$\begin{array}{l}\text { Cycle } \\
\text { two }\end{array}$ & 19 & 39.6 & 5.75 & & & \\
\hline
\end{tabular}

For cycle two, I had no questionnaire for them. Instead, I relied on my observations on the results of their summative test. From my observations, I saw that their answers lacked quality. For example if I told my students to find the area of a geometrical shape, they will only show the answer, with some of the workings but without any descriptions or details of steps to be done. They seemed to neglect writing down all the steps in answering the questions, also they were not as detailed in their answers as Cycle one. Their answers were mathematically correct; however they seemed to solve the questions as mathematicians and not as mathematics teachers. Also in another type of questions such geometrical transformations, I observed that student teachers of cycle two drew the transformation without given explanations and justifications. While student teachers of cycle one answered with some illustrations and details of the answers they gave, which indicate that they have higher level of understanding. These examples highlight the effect and importance of the journal writing on the student teachers' career. It helps them develop the skills that will enable the student teachers to teach more effectively. For example, student teachers in cycle one are more likely to explain a lesson better than cycle two students. Cycle one student teachers will be able to provide their students in the future with the full steps, examples, and relationships. As for students in cycle two, they will not be able to do all that cycle one can easily do. This is a result of the practice of writing journals while taking this course (figure2).

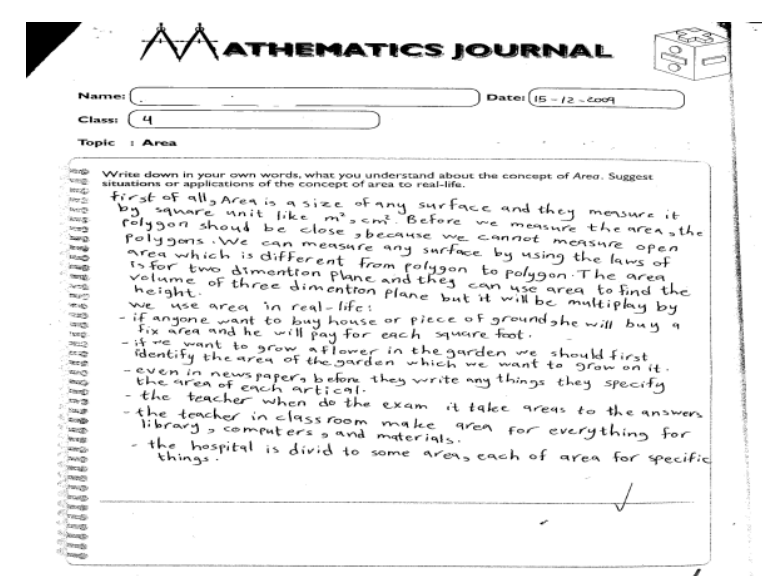



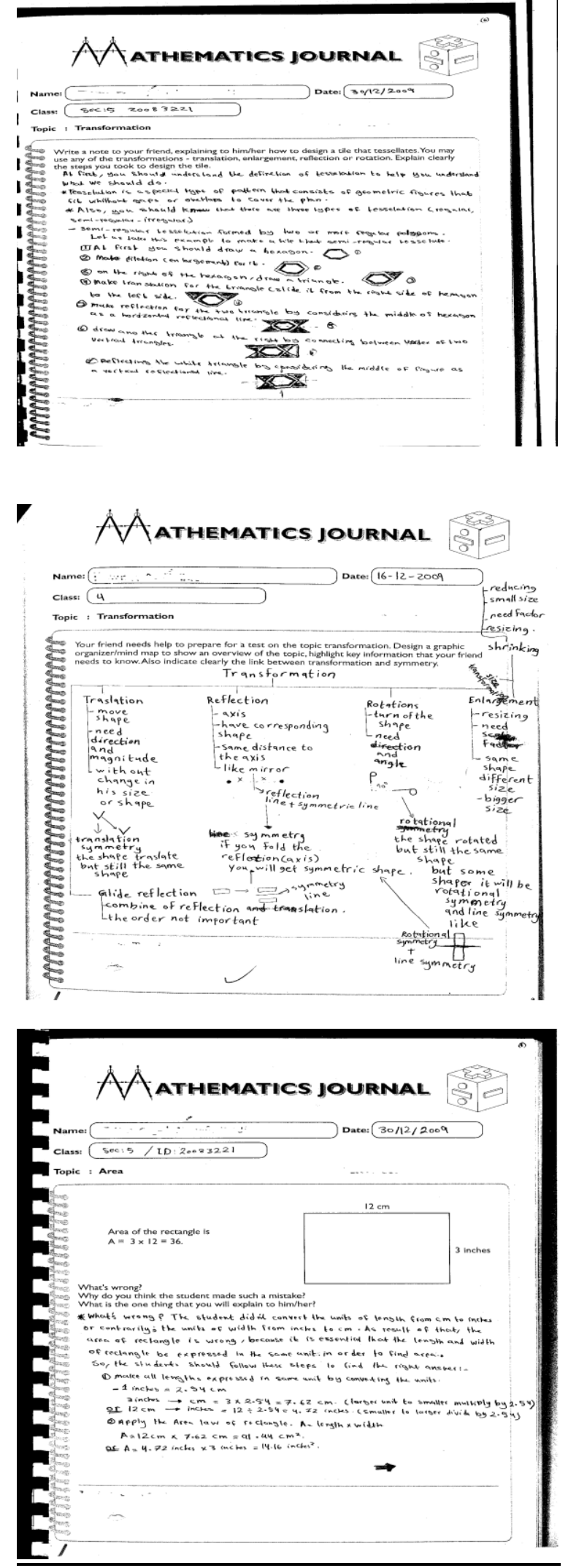

Figure 2. Sample of students' journal writings responses

\subsection{Reflection}

I mentioned earlier that the student teachers solved the questions I gave them as mathematicians and not teachers. This is a problem because teaching math to a student requires a certain approach. Teachers must be able to ensure that the student is fully aware of how the answer was obtained. In my opinion, this can be avoided by getting them out of the habit of just answering the questions and not showing all the steps. The journal writing encourages the writer to explain rather than answer only. Next time, I think I will construct the questions given in the traditional homework, in a way where they earn points for showing the steps rather than just producing the answer.

Cycle two only scored around 5 percent less than cycle one in the summative test. Therefore the difference is not significant (obtained by t-test). So we cannot say that journal writing had a positive effect on the students' understanding of the subject . However, one cannot overlook the skills students in cycle one learned that will help them in their career as a teacher. Also, another negative aspect of the type of assignment given to cycle two is that whatever they hand in to me, it does not always show if the student understands all aspects of the lesson, however we can let them explain every aspect of the lesson if they use the journal writing. Explaining the lesson when using any type of communication such as the journal writing, will allow the student to understand what is being taught better. Also, it gives the students one of required for teachers [23].

\section{Implications and recommendations}

I plan to continue using the writing journal method, because I believe it has great potential in the academic field. My goal is to produce even better grades using the writing journal method, just like others who have achieved a great significant change (Meel [19]; Evans,[7]; Millican, [20] ;Stewart[27]; Shepard [26] \& Human[10]). To my students, this is the first year and the first time for many of them where they are required to write a journal. I believe that if they continue to do so, I might be seeing even better results than the ones they have produced this course. Also, student teachers who practice using the journal writing will indefinitely be able to express themselves better, whether it is in their career or life.

I am still very interested in the positive results journal writing has, so I would see myself in the future researching more about the use of journal writing. I plan on making or finding a way to make journal writing a common thing when teaching student teachers geometry. However, further research is needed on journal writing, for example we need to know it's effectiveness on gender, or students who have different levels of achievements and abilities. 
We also need to find a way to make the journal writings more focused on specific lessons in a certain chapter. I think that future textbooks should contain a few journal writings assignments, as well as a couple of questions that award points for solving the questions and showing all the steps.

I strongly recommend the implementation of journal writing in different fields of mathematics such as algebra and statistics. Especially in universities that have a teacher training program. This is because journal writing can help future teachers develop skills that I think are extremely important. This action research is merely another attempt to make teaching better, and to improve the students' grades and allow them to develop skills that are vital to the modern day teacher.

\section{References}

[1] Bangert-Drowns, R. L., Hurley, M. M., \& Wilkinson, B., (2004).The effects of school-based writing-to-learn interventions on academic achievement: A meta-analysis. Review of Educational Research, 74(1), 29-58.

[2] Boscolo, P. \& Mason, L., (2001).Writing to learn, writing to transfer. In P. Tynjala, L.Mason, \& K. Lonka (Eds.), Writing as a learning tool (pp. 83-104). Dordrecht, The Netherlands: Kluwer Academic Publishers.

[3] Chapman, K.P., (1996). Journals: Pathways to thinking in second-year algebra. Mathematics Teacher, 89(87), 588590.

[4] Countryman, J., (1992). Writing to Learn Mathematics, Porthsmouth, NH: Heinemann.

[5] Dewey, J., (1938). Experience and Education, Collier Books, New York.

[6] Dipillo, M . L., Sovchikr \& Moss, (1997). Exploring Middle Graders' Mathematical Thinking through Journals. Mathematics Teaching in the Middle School, 2, 5, 308-14

[7] Evans, C. S., (1984), Writing to learn in math. Language Arts, 61, 923-835.

[8] Goldsby, D., \& Cozza, B., (2002). Writing samples to understand mathematical thinking. Mathematics Teaching in the Middle School, 7, 517-520.

[9] Hahnemann, B.K., (1986). Journal writing: a key to promoting critical thinking in nursing students. $J$ Nurs Educ.25, 213-215.

[10] Human, P. W., (1993). The effects of process journal writing on learning in mathematics: A study of metacognitive processe (Doctoral Dissertation, East Texas State University, 1992). Dissertation Abstracts International, 53, 3796A.

[11] Jurdak, M. and Zein, R.A., (1998). The effect of journal writing on achievement in and attitudes toward mathematics. School Science and Mathematics, 98 (8), 412-419.

[12] Kaur, B., (2004). Journal writing in the Mathematics Classroom: A resource teachers by teachers. National Institute of Education, Nanyang Technological University: Singapore.

[13] Lindquist, M. M., and Elliott, P. C., (1996), ommunication - an imperative for change: A conversation with Mary Lindquist. In P.C. Elliot \& M. J. Kenney (Eds.), Communication in mathematics, $K-12$ and beyond (pp. 110). Reston, VA: NCTM.

[14] Phillips, B. B., (1993). Writing to learn mathematics: The effect of writing/discussion versus discussion-only on intermediate and delayed test performance in trigonometry (Doctoral Dissertation, University of Maryland College Park, 1993). Dissertation Abstract International, 54,1660A.

[15] Porter, M. K., \& Masingila, J. O., (2000). Examining the effects of writing on conceptual and procedural knowledge in calculus. Educational Studies in Mathematics, 42, 165-177.

[16] Pugalee, D. K., (2005). Writing for mathematical understanding. Norwood, MA:Christopher Gordon Publishers.

[17] Pugalee, D. K \& Lim, L., (2009) The Effects of Writing in a Secondary Applied Mathematics Class:A Collaborative Action Research Project. A manuscript submitted to the AR Expeditions On-Line Journal $\mathrm{http} / / /$ arexpeditions.montana.edu/2009/06/the-effects-ofwriting-in-a-secondary-applied-mathematics-class-acollaborative-action-research-project/

[18] Madden, B. R., (1993), An investigation of the relationship between journal writing and mathematical achievement of fifth-grade students in a rural unit school district (Doctoral Dissertation, Southern Illinois University at Edwardsville, 1992). Dissertation Abstracts International, 54(2), 451A.

[19] Meel, D. E., (1999). Email dialogue in a college calculus classroom: A look at the implementation and benefits. Journal of Computers in Mathematicsand Science Teaching, 18, 387-413.

[20] Millican, B. R., (1994). The effects of writing-to learn tasks on achievement and attitude in mathematics (Doctoral Dissertation, University of North Texas, 1994). Dissertation Abstracts International, 55(4), 897A

[21]National Council of Teachers of Mathematics, (1989), Curriculum and evaluation standards for school mathematics. Reston, VA: NCTM.

[22] Nelson, N. (2001).Writing to learn: One theory, two rationales. In P. Tynjala, L. Mason, \& K. Lonka (Eds.), Writing as a learning tool (pp. 23-36). Dordrecht, The Netherlands: Kluwer Academic Publishers.

[23] Saunders, S. \& Mills, A.M., (1999).The knowledge of communication skills of secondary graduate student 
teachers and their understanding of the relationship between communication skills and teaching. Paper presented at AARE conference- Melbourne.

[24] Samsa, G., \& Oddone, E. Z., (1994). Integrating scientific writing into a statistics curriculum: A course in statistically based scientific writing. The American Statistician, 48(2), 117-119.

[25] Shaw, J. G., (1983). Mathematics students have a right to write. Arithmetic Teacher, lQ(9), 16-18.

[26] Shepard, R. G., (1993). Writing for conceptual development in mathematics. Journal of Mathematical Behavior, 12, 287-293.

[27] Stewart, C. B., (1993). Journal writing in mathematics classrooms: A practical inquiry (Doctoral Dissertation, Memphis State University, 1992). Dissertation Abstracts International, 53, 4242A-4243A.

[28] Stewart, C., and Chance, L., (1995). Making connections: Journal writing and the professional teaching standards. Mathematics Teacher, 88(2), 92-95.

[29] Stock, P. S., (1986). Writing across the curriculum. Theory into Practice, 25(2), 97-101

[30] Theoret, M. J.\& Luna, A., (2009). Thinking Statistically in Writing: Journals and Discussion Boards in an Introductory Statistics Course. International Journal of Teaching and Learning in Higher Education, 21(1), 57-65. Available: http://www.isetl.org/ijtlhe/

[31]Tynjala, P., Mason, L., \& Lonka, K., (2001). Writing as a learning tool: An introduction. In P. Tynjala, L. Mason, \& K. Lonka (Eds.), Writing as a learning tool: Integrating theory and practice(pp.7-22).The Netherlands:Kluwer Academic Publishers.

[32] Vygotsky, L. S., (1986). Thought and language (translated and edited by Alex Kozulin). Cambridge, MA: MIT Press.

[33] Williams, R.M., Wessel, J., Gemus, M. \& FosterSeargeant, F., (2002). Journal writing to promote reflection by physical therapy students during clinical placements. Physiother Theory Pract. 18, 5-15. 